\title{
Pitiose em animais de produção no Pantanal Matogrossense ${ }^{1}$
}

\author{
Carlos Eduardo P. dos Santos ${ }^{2 *}$, Janio Morais Santurio ${ }^{3}$ e Luiz Carlos Marques ${ }^{4}$
}

\begin{abstract}
Santos C.E.P. dos, Santurio J. M. \& Marques L.C. 2011. [Pythiosis of livestock in the Pantanal, Mato Grosso, Brazil.] Pitiose em animais de produção no Pantanal Matogrossense. Pesquisa Veterinária Brasileira 31(12):1083-1089. Departamento de Clínica Médica Veterinária, Faculdade de Agronomia, Medicina Veterinária e Zootecnia, Universidade Federal de Mato Grosso, Av. Fernando Correa da Costa 2367, Cuiabá, MT 78060-900, Brazil. E-mail: carloseduardo@ufmt.br

An epidemiological study (2009-2010) included cattle and horses affected with pythiosis from farms in Pantanal, Mato Grosso, Brazil. The disease occurred predominantly from November to March annually, period of the local rainy season. The mean annual incidence of pythiosis was $0.22 \%$ and $12.5 \%$ in cattle and horses, respectively. In cattle, the case distribution occurred during the peak of the floods and was restricted to 6 to 18 months of age heifers. Mild perilesional edema and lameness evolved to spontaneous resolution within until 90 days. In horses, pythiosis affected animals of both sexes with 3 to 8 years of age. Reinfection afflicted one horse. The lesions evolved to extensive granulation tissue and 'kunkers' in horses that experienced marked cachexy. Death occurred three to seven months after the beginning of symptoms. The mean mortality rate was $5.88 \%$ and the case fatality rate was $45.45 \%$. Diagnosis was confirmed by ELISA test, PCR, histopathology (HE and Grocott) and isolation of Pythium insidiosum. In the endemic area studied, the disease in cattle did not represent an economic impact; on the other hand, the majority of cases in horses progressed unsatisfactorily. The incidence of pythiosis in horses was 57.23 times the incidence recorded in cattle, with statistical significance. While environmental flooded conditions were the same, such difference might be associated with species susceptibility, behavior and management.
\end{abstract}

INDEX TERMS: Oomycetes, pythiosis, horses, cattle, epidemiology, Pythium insidiosum.

RESUMO.- Realizou-se, em quatro propriedades rurais no Pantanal Matogrossense, em 2009 e 2010, um estudo clínico e epidemiológico da pitiose em bovinos e equinos. A enfermidade ocorreu predominantemente entre os meses de novembro e março, correspondendo ao período chuvoso na região. A incidência média anual foi de $0,22 \%$ e $12,5 \%$

\footnotetext{
${ }^{1}$ Recebido em 4 de julho de 2011.

Aceito para publicação em 5 de setembro de 2011.

${ }^{2}$ Programa de Pós-Graduação em Medicina Veterinária, Área de Concentração Clínica Médica Veterinária, Universidade Estadual Paulista (Unesp), Jaboticabal, SP 14870-000, Brasil. Endereço do autor: Departamento de Clínica Médica Veterinária, Faculdade de Agronomia, Medicina Veterinária e Zootecnia, Universidade Federal de Mato Grosso (UFMT), Av. Fernando Correa da Costa 2367, Bairro Boa Esperança, Cuiabá, MT 78068900, Brasil.*Autor para correspondência: carloseduardo@ufmt.br

${ }^{3}$ Laboratório de Pesquisas Micológicas, Departamento de Microbiologia e Parasitologia, Universidade Federal de Santa Maria (UFSM), RS 97105900, Brasil.

${ }^{4}$ Departamento de Clínica e Cirurgia Veterinária, Faculdade de Ciências Agrárias e Veterinárias, Unesp, Jaboticabal, SP.
}

em bovinos e equinos, respectivamente. Nos bovinos, a distribuição dos casos ocorreu no ápice das cheias e restringiu-se a novilhas de 6 a 18 meses de idade, nas quais as lesões cutâneas estiveram associadas com edemas perilesionais discretos e claudicações, mas curaram espontaneamente, em um período máximo de 90 dias. Nos equinos, a pitiose acometeu animais de ambos os sexos, de três a oito anos de idade e registrou-se um caso de reinfecção. A doença evoluiu com agravos no sítio lesional, com desenvolvimento de extenso tecido de granulação, kunkers em permeio à lesão, acentuada caquexia e mortes, as quais ocorreram entre três e sete meses após o início dos sinais. A mortalidade média foi $5,88 \%$ e a letalidade $45,45 \%$. A confirmação do diagnóstico incluiu ELISA-teste, PCR, histopatologia (HE e Grocott) e isolamento de $P$. insidiosum. $\mathrm{Na}$ área endêmica estudada, a enfermidade não causou impacto econômico em bovinos, a despeito da evolução insatisfatória registrada na maioria dos equinos. Nesse estudo, a incidência de pitiose em equinos foi 57,23 vezes a observada em bovinos, 
com significância estatística. Apesar das mesmas condições ambientais, tal diferença foi provavelmente associada com susceptibilidade, comportamento e manejo das espécies nos campos alagados.

TERMOS DE INDEXAÇÃO: Oomicetos, pitiose, equinos, bovinos, epidemiologia, Pythium insidiosum.

\section{INTRODUÇÃO}

A pitiose é uma enfermidade piogranulomatosa do tecido subcutâneo causada por Pythium insidiosum, microorganismo classificado no Reino Straminipila, Classe Oomycetes, Ordem Peronosporales e Família Pythiaceae (Santurio et al. 2006a). A pitiose tem sido descrita em equinos, bovinos, caprinos, ovinos, caninos, felinos, humanos (Alexopoulos et al. 1996), mamíferos selvagens (Camus et al. 2004) e aves (Pesavento et al. 2008). A doença é intimamente associada com o contato de animais e humanos com águas contaminadas com zoósporos móveis, forma infectante de P. insidiosum. Não há predisposição por sexo, idade, ou raça, nem há relato de transmissão direta entre animais, ou entre animais e humanos (Mendoza et al. 1996, Gaastra et al. 2010).

O prejuízo provocado pela pitiose em equinos, espécie mais atingida, é bem documentado e inclui disfunção, custos de tratamento e mortes esporádicas (Mendoza \& Alfaro 1986, Leal et al. 2001, Frey Jr et al. 2007). Em ovinos, embora pouco relatada, o curso clínico é grave e com desfecho fatal (Tabosa et al. 2004, Santurio et al. 2008). Em contrapartida, nos casos em bovinos, predomina cura espontânea (Santurio et al. 1998, Pérez et al. 2005, Gabriel et al. 2008, Grecco et al. 2009).

Devido à dificuldade de diferenciar pitiose de outras infecções fúngicas, o diagnóstico deve incluir, além da histopatologia, outros métodos. Isolamento e identificação do microrganismo (Lacaz et al. 2002) nem sempre apresenta êxito. A identificação precoce da doença, no entanto, é difícil através desses métodos, mas a sorologia por ELISA apresenta boas sensibilidade e especificidade (Lacaz et al. 2002, Santurio et al. 2006b, Dial 2007). Imuno-histoquímica e reação em cadeia de polimerase podem ser utilizadas em tecidos apropriadamente preservados (Rodrigues et al. 2006, Dial 2007, Gabriel et al. 2008). Esse trabalho relata, comparativamente, a dinâmica e o perfil da pitiose em hospedeiros bovinos e equinos, além de enfatizar os aspectos epidemiológicos da doença no Pantanal Matogrossense, Brasil.

\section{MATERIAL E MÉTODOS}

Os dados foram obtidos em quatro propriedades, onde foram relatados casos suspeitos da enfermidade em equinos e bovinos, nas áreas rurais distribuídas ao longo da rodovia Transpantaneira, município de Poconé, MT. Foram incluídos no estudo animais que desenvolveram lesões cutâneas com formação de tecido de granulação no período 2009-2010. Esse estudo associou método descritivo observacional com analítico comparativo, entre espécies estudadas.

Fragmentos de tecidos mantidos em temperatura ambiente e também refrigerados, obtidos por biópsias incisionais de sete bovinos e onze equinos foram coletados e encaminhados aos Laboratórios de Microbiologia e Patologia Veterinária (LMV e LPV) e Biologia Molecular da Universidade Federal de Mato Grosso (UFMT), bem como ao Laboratório de Pesquisas Micológicas (LAPEMI) da Universidade Federal de Santa Maria (UFSM), neste para isolamento e cultivo do agente causal. Para o isolamento, fragmentos de tecidos afetados, obtidos por biópsia foram lavados em água estéril e em seguida semeados em tubos com tampa de rosca contendo Meio Mínimo, Agar Saboraud Dextrose (ASD) e Micosel e, após foram incubados a $37^{\circ} \mathrm{C}$, por 48 horas. A identificação considerou características macroscópicas e microscópicas de $P$. insidiosum, além da indução da zoosporogênese (Pereira et al. 2007). Adicionalmente, realizou-se caracterização molecular (PCR) nos tecidos, segundo Botton et al. (2011), com primer específico para P. insidiosum.

Para a histopatologia, fragmentos de tecidos foram fixados em formalina $10 \%$, processados por técnicas de rotina, corados pela hematoxilina-eosina (HE) e prata-metenamina de Grocott (GMS) (Prophet et al. 1992). Amostras sorológicas dos animais acometidos foram testadas para anticorpos específicos anti-Pythium pelo ensaio imunoenzimático indireto em fase sólida, no LAPEMI (Santurio et al. 2006b).

Para o estudo de novos casos em uma população de indivíduos sob risco, durante intervalo de tempo específico (estudo prospectivo), adotou-se incidência como medida de frequência (Hennekens \& Buring 1987). Face à frequência esperada em qualquer uma das quatro células ser inferior a 5, utilizou-se o teste exato de Fischer, através do Programa Epi Info, versão 6.0 (Dean et al. 2001) e verificou-se o risco relativo de bovinos e equinos desenvolverem a doença (Petrie \& Watson 2009).

\section{RESULTADOS}

Os casos distribuíram-se nos meses de dezembro a abril de 2009 e 2010, com maior concentração em dezembro e janeiro que corresponde ao ápice do período chuvoso na região. 0 perfil epidemiológico sumarizado das ocorrências está apresentado no Quadro 1 . Em bovinos, a ocorrência variou de 0,15 a $3,64 \%$ e não houve nenhuma morte. Em equinos, registrou-se 5,88 a $28,57 \%$ de incidência,

Quadro 1. Perfil epidemiológico de pitiose cutânea em animais de produção (2009-2010), em quatro propriedades rurais no município de Poconé, Pantanal Matogrossense

\begin{tabular}{|c|c|c|c|c|c|c|c|c|c|c|}
\hline \multirow[t]{2}{*}{$\mathrm{PR}^{\mathrm{a}}$} & \multirow[t]{2}{*}{ Ano } & \multicolumn{4}{|c|}{ Bovinos } & \multicolumn{5}{|c|}{ Equinos } \\
\hline & & $\begin{array}{c}\text { № de } \\
\text { expostos }\end{array}$ & $\begin{array}{l}\text { № de } \\
\text { casos }\end{array}$ & $\begin{array}{c}\text { Incidência } \\
(\%)\end{array}$ & $\begin{array}{c}\text { Mortalidade } \\
(\%)\end{array}$ & $\begin{array}{c}\text { № de } \\
\text { expostos }\end{array}$ & $\begin{array}{l}\text { No de } \\
\text { casos }\end{array}$ & $\begin{array}{c}\text { Incidência } \\
(\%)\end{array}$ & $\begin{array}{l}\text { Mortalidade } \\
(\%)\end{array}$ & $\begin{array}{c}\text { Letalidade } \\
\text { (\%) }\end{array}$ \\
\hline 1 & 2009 & 550 & 01 & 0,18 & 0 & 17 & 01 & $5,88^{b}$ & 5,88 & 100 \\
\hline 2 & 2009 & 600 & 01 & 0,17 & 0 & 32 & 03 & $9,38^{c}$ & 00 & 00 \\
\hline 3 & 2010 & 55 & 02 & 3,64 & 0 & 07 & 02 & $28,57^{b}$ & 28,57 & 100 \\
\hline 4 & 2010 & 2000 & 03 & 0,15 & 0 & 32 & 05 & $15,63^{c}$ & 6,25 & 40 \\
\hline & Total & 3205 & 07 & 0,22 & 0 & 88 & 11 & 12,5 & 5,68 & 45,45 \\
\hline
\end{tabular}

${ }^{\mathrm{a}}$ Propriedade rural, ${ }^{\mathrm{b}}$ não tratados, ${ }^{\mathrm{c}}$ tratados. 
com índices de mortalidade e letalidade similares, variando de 40-100\%. A preferência dos bovinos por áreas mais secas (coxilhas) para pastejo e permanência contrastou com o comportamento registrado em equinos que se mantinham em locais com acúmulos de água (baías ou lagoas), pastagens inundadas com drenagem lenta e vegetação aquática abundante (Fig.1). Além disso, a condução dos bovinos às áreas mais secas era prática de manejo usual, em situação de cheias. Houve associação entre a espécie e a incidência da doença. 0 risco para equinos foi $12,5 \%$ e, para bovinos, $0,22 \%$, conforme disposto no Quadro 2. A incidência de pitiose em equinos foi 57,23 (risco relativo) vezes a observada em bovinos (teste de exato de Fisher; $\mathrm{P}<0,0001$ e Intervalo de Confiança a 95\% variando de $22,72$ a 144,14$)$.

Sete casos foram registrados em bovinos, todos em novilhas (6 a 18 meses), com graus variados de mestiçagem e bom escore corporal. As lesões cutâneas apresentavam-se usualmente apendiculares distais, únicas ou múltiplas e, inicialmente (até dez dias), circunscritas e com superfícies planas, hemorrágicas, úmidas e brilhantes (Fig.2). Nas fases mais tardias (20 a 40 dias), seguia-se a forma elíptica, às vezes disforme, com superfície ressequida e hiperêmica. $\mathrm{Na}$ fase de resolução, apresentavam bordas em linha escuras e

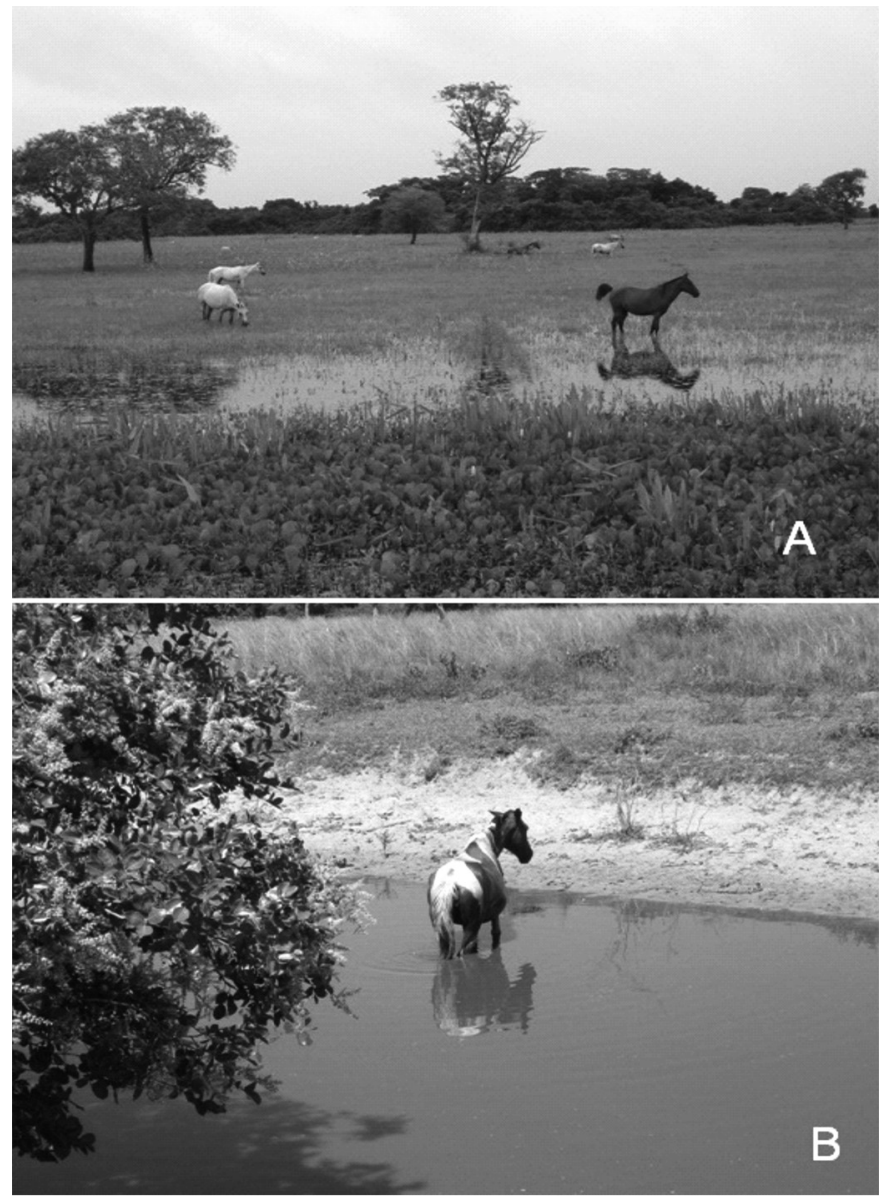

Fig.1. (A) Equinos distribuídos nos campos do Pantanal Matogrossense durante o período de cheia (fevereiro de 2010) com abundante vegetação aquática. (B) Equino no período de estiagem (setembro de 2009) em estação em uma lagoa eutrofizada.
Quadro 2. Estudo de coorte sobre pitiose cutânea em animais de produção de quatro propriedades rurais do Pantanal Matogrossense (2009-2010)

\begin{tabular}{ccccc}
\hline \multicolumn{5}{c}{ Pitiose cutânea } \\
\hline Espécie & Sim & Não & Total & Risco / Risco relativo \\
\cline { 2 - 3 } Equinos & 11 & 77 & 88 & $11 / 88^{\mathrm{Re}}$ \\
Bovinos & 07 & 3198 & 3205 & $7 / 3205^{\mathrm{Rb}}$ \\
\cline { 2 - 3 } Total & 18 & 3275 & 3293 & $57,23^{\mathrm{RR}}$ \\
\hline
\end{tabular}

$\mathrm{R}_{\mathrm{e}}=$ Risco equino, $\mathrm{R}_{\mathrm{b}}=$ Risco bovino, $\mathrm{RR}=$ Razão de risco ou risco relativo Teste exato de Fisher; Intervalo de Confiança a 95\% (22,72-144,14).

angulares (Fig. 3). Discreto edema adjacente foi identificado em seis novilhas e claudicação, em duas. 0 caso mais persistente (mais de 60 dias) foi associado com edema e ulceração profunda, além de claudicação. Nenhum caso bovino foi tratado e todos curaram espontaneamente, sem qualquer registro de perda de escore corporal. 0 tempo para remissão total das lesões foi de três semanas a três meses.

Os equinos sem raça definida $(n=6)$, ou da raça pantaneira $(n=5)$ apresentavam bom estado corporal inicial, porém, verificava-se rápida perda de peso a partir da segunda ou terceira semana de evolução da lesão cutânea. Os casos

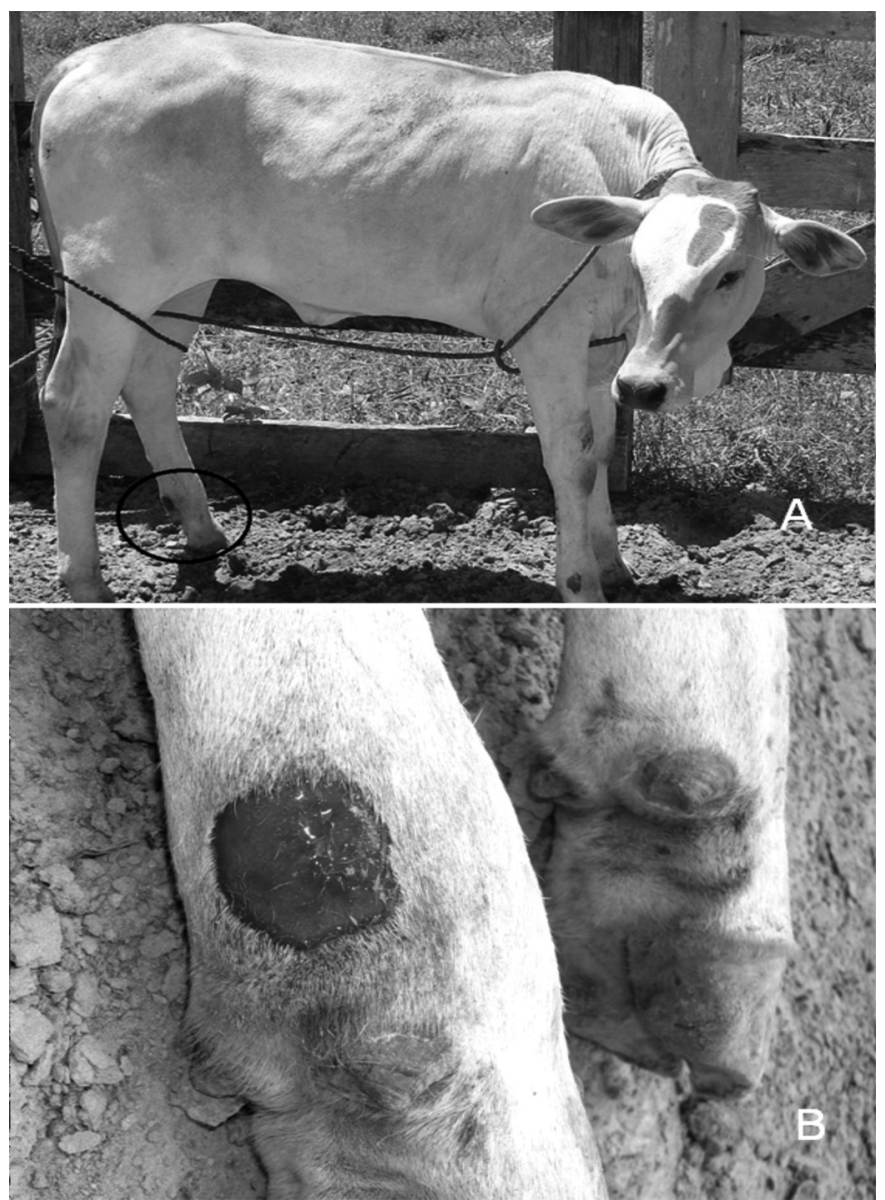

Fig.2. (A) Novilha, 5 meses de idade, com lesão cutânea distal no membro pélvico, decorrente de pitiose. (B) Padrão circunscrito, superfície úmida, vermelha e brilhante em lesão recente, com menos de 10 dias de evolução. 


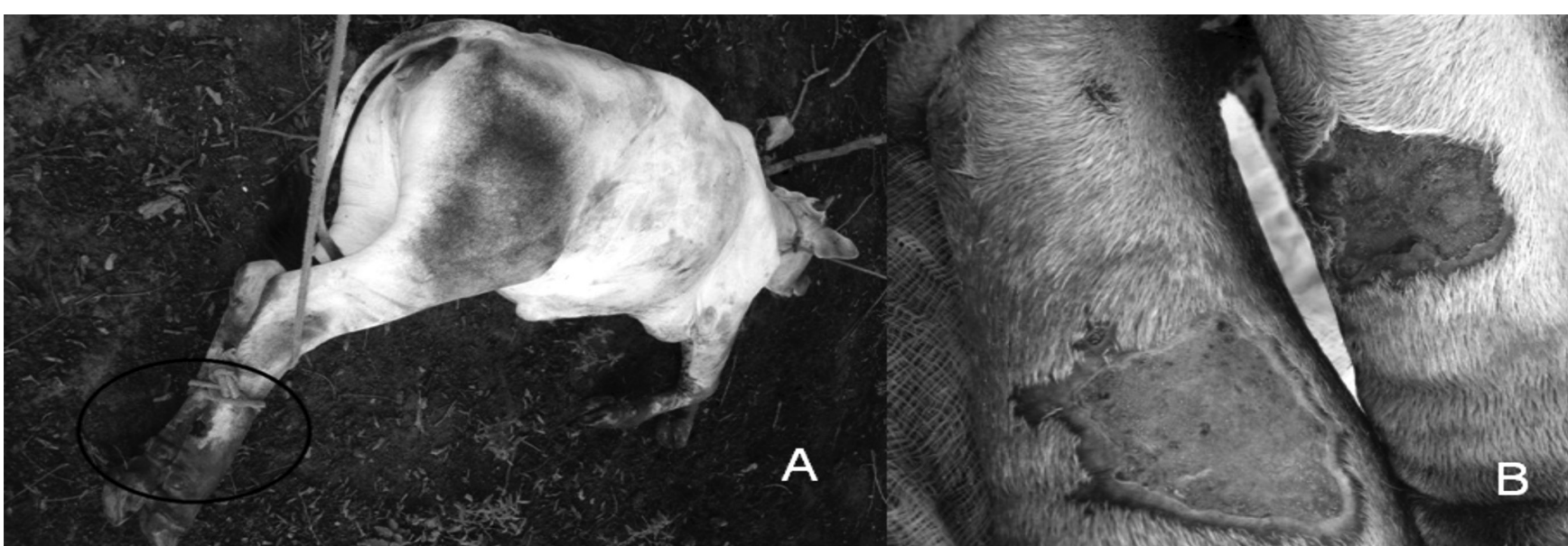

Fig.3. (A) Novilha, 12 meses de idade, com lesões distais nos membros pélvicos, decorrentes de pitiose. (B) Lesões cutâneas em diferentes graus de resolução, padrão disforme, com bordas angulares, coloração avermelhada, moderadamente ressequida, com discretos focos hemorrágicos, entre 20 e 40 dias de evolução.

afetaram onze equinos adultos com 3 a 8 anos de idade. As lesões eram de localização axial ou apendicular (proximal ou distal), únicas ou múltiplas (Fig.4) e, inicialmente (até 20 dias de evolução), circunscritas, com superfície central côncava e bordas proeminentes, mas à medida que cronificavam, tornavam-se elípticas com superfície central projetada, friáveis e com secreções serosanguinolentas. Às vezes, havia sinus e focos necróticos de onde era possível extrair kunkers (materiais brancos ou amarelados semelhantes a corais), com dois a $20 \mathrm{~mm}$. Esses kunkers aumentavam proporcionalmente à condição temporal da lesão. Um caso foi associado a trauma prévio (laceração com arame). Todas as lesões apresentaram caráter progressivo e susceptível a agravos. Três dos 11 equinos não foram submetidos a tratamento e evoluíram em três a sete meses a grave caquexia (Fig.4A) que antecedeu as mortes. De oito equinos tratados com imunoterápicos (Pitium Vac®) associados, ou não, a debridamento cirúrgico, observou-se remissão dos sinais clínicos em seis e refratariedade em dois que morreram, de forma semelhante ao ocorrido nos equinos não tratados. 0 equino que teve lesão abdominal havia desenvolvido pitiose em um membro pélvico, dois anos antes.

P. insidiosum foi isolado somente de amostras de equinos e cresceu em Meio Mínimo como hifas hialinas submersas, parcialmente septadas e com ramificações perpendiculares laterais, em ângulo reto. Nas amostras de bovinos, havia crescimento parcial, porém à repicagem, ocorria contaminação bacteriana secundária.

Nas amostras de bovinos observaram-se à microscopia múltiplos focos de necrose com infiltrado granulomatoso composto por macrófagos, neutrófilos e, por vezes, células gigantes multinucleadas contendo estruturas tubuliformes semelhantes a hifas fúngicas. Havia intensa proliferação de tecido de granulação, acantose e hiperqueratose e, na derme, observou-se infiltrado granulomatoso perivascular moderado com presença de macrófagos e eosinófilos. Nas amostras de equinos, havia intensa proliferação de tecido de granulação com necrose multifocal contendo imagens negativas tubuliformes de hifas ramificadas e irregulares. Ao redor das áreas de necrose, os infiltrados eram predo- minantemente compostos por eosinófilos, macrófagos e raras células gigantes. Nas duas espécies houve impregnação das hifas pela coloração de prata. As biópsias e as
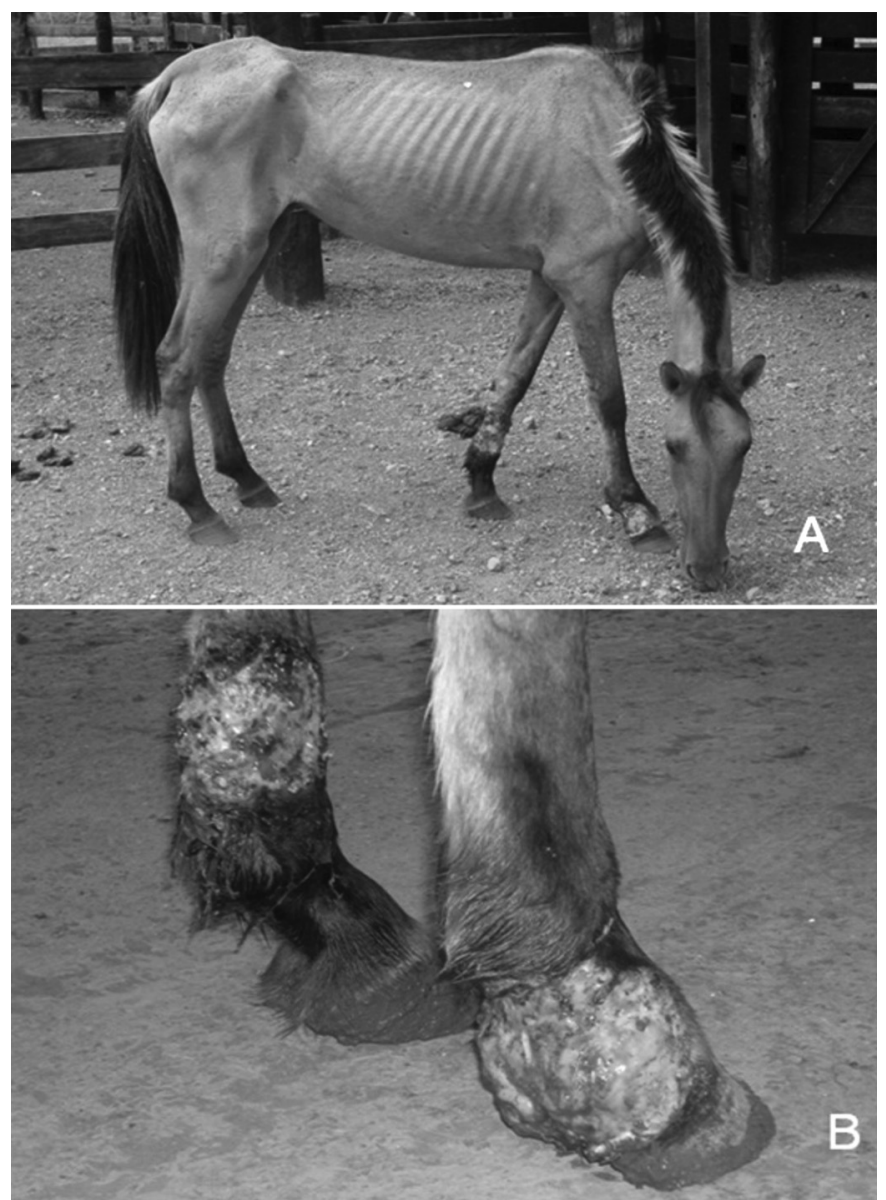

Fig.4. Equino, fêmea, 4 anos de idade, com lesões multifocais decorrentes de pitiose, na extremidade distal de membros torácicos. (A) Severa emaciação do animal afetado após 3 meses de evolução. (B) Detalhe das lesões, com superfície úmida, tecido de granulação, kunkers em permeio do tecido distribuídos principalmente nas bordas. 0 quadro evoluiu para a morte, cerca de 30 dias mais tarde. 
amostras de soro dos animais em concordância com achados histológicos foram sororreagentes no teste de ELISA e, através da técnica de PCR, amplificaram um fragmento de aproximadamente $540 \mathrm{pb}$ que caracteriza Pythium insidiosum.

\section{DISCUSSÃO}

0 padrão de distribuição temporal dos casos de pitiose no Pantanal Matogrossense segue o mesmo perfil nos rebanhos estudados, em ambas as espécies estudadas, de forma similar aos registros da Austrália, onde os casos também se concentram em verões chuvosos (Miller et al. 1985, Leal et al. 2001, Santurio et al. 2006a). A frequência de casos na espécie equina é maior que na espécie bovina. Considerando a proporção entre o número de animais expostos e os que desenvolveram a doença no período estudado, pode-se dizer que a incidência da pitiose em equinos foi 57,23 vezes a observada em bovinos. Embora expostos às mesmas condições ambientais, o padrão de comportamento das espécies possivelmente influenciou a ocorrência da doença, pois os equinos se mantiveram mais tempo nos locais alagadiços, em comparação com os bovinos, os quais preferiam, ou eram conduzidos às coxilhas nas situações de alagamentos. Assim, equinos têm maior risco de contato com as formas infectantes do agente. Entretanto, os bovinos apenas permaneciam em locais inundados espontaneamente, se não houvesse a alternativa de alimento e refúgio em áreas mais altas e secas. São reconhecidas essas influências ambientais e a presença de zoósporos infectantes em locais de vegetação aquática abundante e alta temperatura (Mendoza et al. 1996, Santurio et al. 2006a, Gaastra et al. 2010). Essas particularidades podem estar associadas com a frequência em bovinos somente no pico da cheia e uma maior frequência por períodos mais extensos em equinos. Outros relatos associam áreas alagáveis com casos de pitiose, tanto em bovinos (Gabriel et al. 2008, Grecco et al. 2009), quanto em equinos (Leal et al. 2001, Santurio et al. 2006a). Ressalta-se que vários aspectos podem mascarar quantitativamente as ocorrências nos bovinos, subestimando-as. Entre estes, incluem-se lesões apendiculares distais recobertas parcialmente por barro (difícil visualização), curso clínico não tão prolongado (quanto em equinos), manejo em áreas extensas e de vegetação abundante, manejo pouco frequente associado com grande número de animais e ausência de comprometimento orgânico mais severo. Questionamentos semelhantes foram discutidos por Grecco et al. (2009).

Na população estudada, a enfermidade acometeu bovinos jovens e equinos adultos. Os aspectos da apresentação clínica da pitiose em bovinos jovens (Miller et al. 1985, Santurio et al. 1998, Pérez et al. 2005, Gabriel et al. 2008) ou equinos adultos (Santos et al. 1987, Leal et al. 2001, Santurio et al. 2006a, Frey Jr et al. 2007) têm sido amplamente descritos. A regressão espontânea das lesões em bovinos contrastou drasticamente com a evolução desfavorável da doença em equinos, os quais inclusive, em períodos similares de tempo, apresentavam considerável perda de peso, além de mortes. Acredita-se que a participação de mediadores inflamatórios seja responsável pelo quadro de caquexia nos equinos (Leal et al. 2001).
Cursos clínicos de ampla cronicidade, com perda de peso em equinos submetidos ou não a tratamentos e seguidos por mortes foram frequentemente relatados (Santos et al. 1987, Alfaro \& Mendoza 1990, Leal et al. 2001, Frey Jr et al. 2007, Maciel et al. 2008). Ressalta-se que todos equinos não tratados, além de dois (dos oito) tratados com imunoterapia, morreram. Por certo, mesmo com tratamentos diversificados, a maioria dos casos crônicos é fatal (Mendoza \& Alfaro 1986, Alfaro \& Mendoza 1990). A imunoterapia no grupo de animais tratados impossibilita quaisquer suposições associadas com o curso natural dos casos sem a intervenção.

Provavelmente, padrões diferenciados de resistência entre espécies susceptíveis relativos à imunidade inata e adquirida influenciam o perfil de apresentação clínica. Reforça tal hipótese o padrão histológico da lesão, também, diferenciado e homogêneo entre as espécies estudadas. No sítio lesional, os bovinos apresentaram populações celulares compostas por polimorfonucleares, predomínio de macrófagos e células gigantes. Relatos prévios concordam com esse aspecto (Pérez et al. 2005, Gabriel et al. 2008, Grecco et al. 2009). A imunidade inata, considerada mecanismo inespecífico da resposta imune, constitui a primeira linha de defesa contra infecções, sem necessidade de sensibilização prévia e é caracterizada por fagocitose e digestão de microrganismos e substâncias estranhas por macrófagos e leucócitos (Medzhitov \& Janeway 1997, Aderem \& Ulevitch 2000). A célula gigante originada a partir de múltiplas divisões nucleares sem divisão do citoplasma tem maior função secretora de enzimas, além de grande capacidade de fagocitose (Tizard 2002), provavelmente tendo importante papel na destruição de hifas. Isto sugere que, em bovinos, o reflexo da eficiente imunidade inata seria o rápido curso clínico em animais predominantemente jovens, imaturos imunologicamente. Por sua vez, a ativação da resposta imune inata, desencadeia uma rede de citocinas, pré-requisito da imunidade adquirida (Akira et al. 2001, Kokkinopoulus et al. 2005). Assim, a imunidade adquirida ativada preveniria o desenvolvimento da doença em bovinos adultos, conforme observado aqui e em outros estudos (Santurio et al. 1998, Pérez et al. 2005, Gabriel et al. 2008, Grecco et al. 2009).

Nos equinos, o padrão histológico incluiu infiltrados predominantemente eosinofílico e raras células gigantes. Segundo Miller \& Campbell (1984), os kunkers encontrados nessa espécie apresentam-se como coágulos eosinofílicos de tamanhos variados compostos de hifas, colágeno e células inflamatórias. De acordo com Miller (1981), mesmo antigênicas, as hifas não são completamente reconhecidas pelo hospedeiro devido à marcante ação inflamatória. Provavelmente, o mecanismo de evasão de $P$. insidiosum do sistema imune do hospedeiro equino seja mais eficiente e fragilize tanto a resposta inata o que pode estar associado com curso clínico crônico e morte precedida de caquexia progressiva (Leal et al. 2001), quanto a adquirida, considerando a incidência em equinos adultos e, por vezes, reincidentes, quando de tratamentos diversificados, ou através de excisões cirúrgicas (Leal et al. 2001, Biava et al. 2007). Reinfecções, conforme se verificou em 
um dos equinos (Santos et al. 2011), pode indicar frágil imunidade adquirida. Santurio et al. (2006a) descreve que embora níveis aumentados de anticorpos possam auxiliar a recuperação de equinos que desenvolvam pitiose, os mecanismos envolvidos na cura baseiam-se principalmente na resposta celular, fato sustentado pela alteração tecidual após tratamento com imunoterapia, em que há mudança de inflamação eosinofílica inicial para uma resposta mononuclear, mediada por macrófagos e linfócitos $\mathrm{T}$ ao final da resposta.

Considerando-se frequência, evolução e padrão histológico dos hospedeiros estudados, supõe-se que macrófagos e células gigantes, além de outras particularidades relativas à imunidade inata e adquirida, têm papel essencial na patogênese da pitiose e que são necessários estudos adicionais sobre os mecanismos relacionados com a fagocitose desse oomiceto por essas células e suas funções.

Em conjunto, achados epidemiológicos, clínicos e histopatológicos foram consistentes para o diagnóstico de pitiose em todos os casos estudados e apresentaram total concordância com testes de ELISA, tanto para os equinos, quanto para os bovinos. Isolou-se o patógeno das amostras de equinos, porém dificuldades com relação ao isolamento das amostras provenientes de bovinos foram marcantes, como ocorrido previamente (Pérez et al. 2005, Gabriel et al. 2008, Grecco et al. 2009). 0 isolamento, além de requerer tempo, pode gerar resultado falso negativo. Assim, a reação em cadeia de polimerase foi fundamental para consolidar o diagnóstico nos tecidos dos bovinos analisados (Dial 2007, Gaastra et al. 2010).

As informações deste estudo descritivo, em caráter comparativo, auxiliam a compreensão dos mecanismos envolvidos na pitiose em ambas as espécies. Além disso, os aspectos epidemiológicos aqui descritos constituem registro importante da ocorrência da doença em animais de produção no Pantanal Matogrossense.

Agradecimentos.- Às equipes de apoio diagnóstico, em especial aos colegas do Laboratório de Patologia Veterinária, Laboratório de Microbiologia Veterinária, Laboratório de Biologia Molecular da UFMT e Laboratório de Pesquisas Micológicas da UFSM. As críticas e opiniões dos Professores L. A. Amaral, L. Nakazato, J. H. G. Scatena e N. J. Segri. Ao suporte financeiro FAPEMAT (Processo 002/282/2007). A CAPES pela concessão de bolsa no Programa Prodoutoral.

\section{REFERÊNCIAS}

Aderem A. \& Ulevitch R.J. 2000. Toll-like receptors in the induction of the innate immune response. Nature 406:782-787.

Akira S., Takeda K. \& Kaisho T. 2001. Toll-like receptors: critical proteins linking innate and acquired immunity. Nat. Immunol. 2:675-680.

Alexopoulus C.J., Mims C.W. \& Blackwell M. 1996. Pythium, Oomycota, p.683-737. In: Ibid. (Eds), Introductory Mycology. $4^{\text {th }}$ ed. John Wiley and Sons, Inc., New York.

Alfaro A.A. \& Mendoza L. 1990. Four cases of equine bone lesions caused by Pythium insidiosum. Equine Vet. J. 22:295-297.

Biava J.S., Ollhoff D.R., Gonçalves R.C. \& Biondo A.W. 2007. Zigomicose em equinos: revisão. Revta Acad., Curitiba, 5:225-230.

Botton S.A., Pereira D.I.B., Costa M.M., Azevedo M.I., Argenta J.S., Jesus F.P.K., Alves S.H. \& Santurio J.M. 2011. Identification of Pythium insidiosum by Nested PCR in cutaneous lesions of Brazilian horses and rabbits. Curr. Microbiol. 62:1225-1229.
Camus A.C., Grooters A.M. \& Aquilar R.F. 2004. Granulomatous pneumonia caused by Pythium insidiosum in a central American jaguar, Panthera onca. J. Vet. Diagn. Invest. 16:567-571.

Dean A.G., Dean J.A. \& Burton A.H. 2001. Epi Info 6 Version 1.2. A Word processing, date base, and statistic program for epidemiology on microcomputaters, Center for Disease Control, Atlanta.

Dial S.M. 2007. Fungal diagnostics: Current techniques and future trends. Vet Clin North Am Small Anim Pract. 37:373-392.

Frey Jr F., Velho J.R., Lins L.A., Nogueira C.E.W. \& Santurio J.M. 2007. Pitiose equina na região Sul do Brasil. Revta Port. Ciênc. Vet. 102:107111.

Gaastra W., Lipman L.J.A., De Cock A.W.A.M., Exel T.K., Pegge R.B.G., Scheurwater J., Vilela R. \& Mendoza L. 2010. Pythium insidiosum: An overview. Vet. Microbiol. 146:1-16.

Gabriel A.L., Kommers G.D., Trost M.E., Barros C.S.L., Pereira D.B., Schwendler S.E. \& Santurio J.M. 2008. Surto de pitiose cutânea em bovinos. Pesq. Vet. Bras. 28:583-587.

Grecco F.B., Schild A.L., Quevedo P., Assis-Brasil N.D., Kommers G.D., Marcolongo-Pereira C. \& Soares M.P. 2009. Pitiose cutânea em bovinos na região Sul do Rio Grande do Sul. Pesq. Vet. Bras. 29:938-942.

Hennekens C.H. \& Buring J.E. 1987. Epidemiology in Medicine. Little, Brown Company, Boston/Toronto. 383p.

Kokkinopoulos I., Jordan W.J. \& Ritter M.A. 2005. Toll-like receptor mRNA expression patterns in human dendritic cells and monocytes. Mol. Immunol. 42:957-968.

Lacaz C.S. 2002. Pitiose, p.770-744. In: Lacaz C.S., Porto E., Martins J.E.C., Heins-Vaccari E.M., Melo N.T. (Eds), Tratado de Micologia Médica Lacaz. $9^{\text {th }}$ ed. Sarvier, São Paulo.

Leal A.B.M., Leal A.T., Santurio J.M., Kommers G.D. \& Catto J.B. 2001. Pitiose equina no Pantanal brasileiro: aspectos clínico-patológicos de casos típicos e atípicos. Pesq. Vet. Bras. 21:151-156.

Maciel I.C.F., Silveira J.T., Maia C.A., Sousa R.M., Oliveira N.J.F. \& Duarte E.R. 2008. Pitiose fatal em equino tratado inicialmente para habronemose cutânea. Acta Sci. Vet. 36:293-297.

Medzhitov R. \& Janeway C.A.J. 1997. Innate immunity: The virtues of a nonclonal system of recognition. Cell 91:295-298.

Mendoza L. \& Alfaro A.A. 1986. Equine pythiosis in Costa Rica: Report of 39 cases. Mycopathol. 94:123-129.

Mendoza L., Ajello L. \& McGinnis M.R. 1996. Infections caused by the oomycetous pathogen Pythium insidiosum. J. Mycol. Med. 6:151-164.

Miller R.I. 1981. Treatment of equine phycomycosis by immunotherapy and surgery. Aust. Vet. J. 57:377-382.

Miller R.I. \& Campbell R.S. 1984. The comparative pathology of equine cutaneous phycomycosis. Vet. Pathol. 21:325-332.

Miller R.I., Olcott B.M. \& Archer M. 1985. Cutaneous pythiosis in beef calves. J. Am. Vet. Med. Assoc. 186:984-986.

Pereira D.I.B., Santurio J.M., Alves S.H., Argenta J.S., Potter L., Spanamberg A. \& Ferreiro L. 2007. Caspofungin in vitro and in vivo activity against Brazilian Pythium insidiosum strains isolated from animals. J. Antimicrob. Chemother. 60:1168-1171.

Pérez R.C., Luis-León J.J., Vivas J.L. \& Mendoza L. 2005. Epizootic cutaneous pythiosis in beef calves. Vet. Microbiol. 109:121-128.

Pesavento P.A., Barr B., Riggs S.M., Eigenheer A.L., Pamma R. \& Walker R.L. 2008. Cutaneous pythiosis in a Nestling White-faced Ibis. Vet. Pathol. 45:538-541.

Petrie A. \& Watson P. 2009. Estatística em Ciência Animal e Veterinária. $2^{\text {a }}$ ed. Roca, São Paulo. 236p.

Prophet E.B., Mills B., Arrington J.B. \& Sobin L.H. 1992. Laboratory Methods in Histotechnology. Armed Forces Institute of Pathology, Washington, DC. $279 \mathrm{p}$.

Rodrigues A., Graça D.L., Fontoura C., Cavalheiro A.S., Hensley A., Schwendler S.E., Alves S.H. \& Santurio J.M. 2006. Intestinal dog pythiosis in Brazil. J. Med. Vet. Mycol 16:37-41. 
Santos M.N., Metzdorf L.L., Braga M.M. \& Wolle C.A. 1987. Pitiose cutânea em equinos do Rio Grande do Sul. Pesq. Vet. Bras. 7:57-61.

Santos C.E.P., Marques L.C., Zanette R.A., Jesus F.P.K. \& Santurio J.M. 2011. Does immunotherapy protect equines from the reinfection by the oomycete Pythium insidiosum? Clin. Vaccine Immunol. Jun. 29 [Published online ahead of print doi:10.1128/CVI.05150-11].

Santurio J.M., Monteiro A.B., Leal A.T., Kommers G.D., Sousa R.S. \& Catto J.B. 1998. Cutaneous pythiosis in calves from the Pantanal region of Brazil. Mycopathol. 141:123-125.

Santurio J.M., Alves S.H., Pereira D.B. \& Argenta J.S. 2006a. Pitiose: uma micose emergente. Acta Sc.Vet.34:1-14.
Santurio J.M., Leal A.T., Leal A.B.M., Alves S.H., Lübeck I., Griebeler J. \& Copetti M.V. 2006b. Teste de ELISA indireto para o diagnóstico sorológico de pitiose. Pesq. Vet. Bras. 26:47-50.

Santurio J.M., Argenta J.A., Schwendler S.E., Cavalheiro A.S., Pereira D.I.B., Zanette R.A., Alves S.H., Dutra V., Silva M.C., Arruda L.P., Nakazato L. \& Colodel E.M. 2008. Granulomatous rhinitis associated with Pythium insidiosum infection in sheep. Vet. Rec. 163:276-277.

Tabosa I.M., Riet-Correa F., Nobre V.M.T., Azevedo E.O., Reis-Júnior J.L. \& Medeiros R.M.T. 2004. Outbreaks of pythiosis in two flocks of sheep in northeastern Brazil. Vet. Pathol. 41:412-415.

Tizard I.R. 2002. Imunidade inata: macrófagos, p.28-38. In: Ibid. (Ed.), Imunologia Veterinária: uma introdução. 6⿳a ed. Editora Roca, São Paulo. 